\title{
Uma aventura epistemológica
}

\author{
An epistemological adventure
}

Entrevista com JESÚS MARTÍN-BARBERO*

Por Maria Immacolata Vassallo de Lopes ${ }^{1}$

A REVISTA MATRIZES TEM buscado no perfil teórico e reflexivo de autores e de textos a marca identitária, e talvez, a principal, de sua proposta editorial. Para inaugurar Entrevista, nova seção da revista, dirigimos um roteiro de questões a Jesús Martín-Barbero de forma a compor o que podemos denominar de pensamento epistemológico deste Autor sobre a comunicação ou a partir da comunicação. Mesmo sendo um dos autores mais citados nos estudos de comunicação no Brasil, ao seguir mais de perto esse pensamento com suas linhas que se espraiam e costuram autores, pesquisas, metodologias e objetos, acreditamos que desta entrevista resulta um texto inédito do Autor, no qual revela a construção de seu modo de pensar o pensamento da comunicação.

MATRIZes: Nossa revista tem o prazer de fazer esta entrevista propondo como eixo central uma reflexão de caráter epistemológico-metodológico. Para isso escolhi como referência alguns de seus textos ou partes de textos onde seu pensamento acerca do trabalho teórico e metodológico aparece mais explícito. Tratei então de canalizar esses textos para algumas questões sobre o pensamento de Jesús Martín-Barbero, hoje.

Em seu artigo seminal intitulado "Retos a la investigación de comunicación en América Latina”, publicado na revista Comunicación y Cultura ${ }^{2}$, havia algumas pistas elucidativas para os pesquisadores latino-americanos, das quais destaco, primeiramente, a questão do trabalho metodológico ser visto como «luxo» em países periféricos como os nossos; e, além disso, você propunha três novos campos estratégicos de investigação denominados "Comunicação

\footnotetext{
* Jesús Martín-Barbero é doutor em Filosofia e Letras pela Universidade de Louvain (Bélgica). Atualmente é coordenador de pesquisa da Faculdade de Comunicação e Linguagem da Pontifícia Universidade Javeriana de Bogotá, membro do Conselho Nacional de Ciências Sociais e do Conselho Nacional de Cultura na Área de Meios Cidadãos da Colômbia.

1. Entrevista realizada em 16 de setembro de 2008 , em São Paulo (SP), por ocasião do curso ministrado pelo Autor no Programa de PósGraduação em Ciências da Comunicação da USP.

2. Ao final da entrevista, são apresentadas as obras citadas pelo Autor, tanto as que foram mencionadas como referências, como aquelas que influenciaram, de alguma forma, seu pensamento.
} 
transnacional", "Novas tecnologias de comunicação" e "Comunicação alternativa e popular". Como você vê essas pistas hoje? Quais seriam os novos campos estratégicos a pesquisar?

Jesús Martín-Barbero: Não posso começar esta conversa com MATRIZes sem agradecer à entrevistadora, e a tantos amigos e colegas brasileiros que têm acompanhado, sustentado e estimulado, longa e profundamente, não somente meu trabalho mas minha vida, ou seja, algo que é mais do que "minha vida de trabalho".

E começarei contando que o que eu quis colocar em debate naquele meu primeiro texto sobre comunicação foi uma dupla pergunta: o que era pesquisável nesse momento dentro do campo da comunicação e o que não era pensável, nem formulável, e por quê? Apareceram, de um lado, os limites que o recorte teórico que traçavam tanto "a escola" norte-americana como a francesa impunham aos latino-americanos; e, de outro, tudo o que alguns de nós vislumbrávamos como necessário e urgente de ser pesquisado, mas para o qual não contávamos nem com categorias conceituais, nem com ferramentas metodológicas que nos permitissem formulá-lo. Daí partiu minha aventura epistemológica: tornar possível outras perguntas que nos exigiam não apenas misturar ingredientes das diversas escolas e disciplinas, mas atrevermo-nos a inventar um outro modo de pensar a comunicação, já não mais a partir da psicologia social norteamericana ou da semiótica francesa, mas a partir «da cultura, das culturas, da nossa própria vida social e cultural».

Os campos estratégicos, naquele momento, tinham um sentido que, acredito, hoje já não tenham. Não porque não possam ser propostos enquanto tais, mas o campo da comunicação passou por transformações muito fortes, não apenas em termos dos cursos de comunicação, mas dos rumos que a própria pesquisa de comunicação tomou. Quando escrevi esse texto, em 1979, estava na presidência da Alaic, que eu iria deixar em 1980. Havia presidido também em 1978-79, e no início de 1979 fiz esse texto aos pesquisadores para criar um grande debate quando deixasse a presidência. Quero dizer que aquela proposta estava muito ligada à convergência que tinha o campo da comunicação enquanto campo de conhecimento.

Havia uma convergência e uma coesão, um desejo de construir um grande projeto de pesquisa em comunicação que realmente tivesse um papel de destaque na própria evolução das Ciências Sociais na América Latina e, portanto, muito vinculado ao momento político que vivíamos, que era, ainda, o momento das ditaduras - agora parte da América do Sul -, mas que já indicava alguns traços de passagem para a democracia. Porém, era um momento muito importante, porque alguns dos grandes pesquisadores exilados começavam a 
retornar a seus países, o que ocorreria poucos anos depois, por exemplo, em 1983, a volta à Argentina. Como dizia, estávamos em um momento que facilitava a construção coletiva desta espécie de mapa de questões estratégicas, que não eram apenas os objetos de estudo, mas os modos como nos aproximávamos deles, e por isso a dimensão epistemológica era algo que estava muito presente.

Justamente a dimensão epistemológica mobilizava essa primeira ideia, nesse texto eu estaria criticando certos preconceitos existentes na própria esquerda latino-americana de que pensar e fazer teoria era um luxo, algo para países ricos, e que nós devíamos ligar diretamente o que pesquisávamos à ação política, que a pesquisa se justificava ao servir dentro de uma estratégia de ação política. O mais interessante é que, justamente naquele momento, começávamos a nos conscientizar de toda a dependência que existia em função da ausência de teoria. Ou seja, não só tínhamos uma teoria da dependência, como também começávamos a ver que boa parte da dependência era dependência intelectual.

Isso se tornou uma realidade clara depois, quando vimos que a imensa maioria dos autores na América Latina continuou olhando para o norte. Não porque não haja teoria na América Latina, que não haja pensamento ou bibliografia, porque já faz algum tempo que começa a haver pensamento próprio; porém, não se acredita que esse pensamento tenha valor, se vem do norte parece ter mais. A esquerda citava os franceses, enquanto a direita citava os norteamericanos. Sabíamos que estávamos presos, mas pelo menos dentro do grupo da Alaic existia uma consciência clara de que era preciso criar um pensamento latino-americano, de que não se tratava simplesmente de misturar coisas que vinham da semiótica com outras do marxismo e da teoria da dependência. Quando os campos foram propostos naquele texto, havia o conhecimento de que cada um deles exigiria renovar epistemologicamente as formas de construir os objetos de conhecimento. Esse momento que, afortunadamente, vivíamos naquele tempo não o encontro hoje, quando o campo da comunicação se encontra completamente cindido, inteiramente fraturado epistemologicamente.

Não digo que não haja núcleos de pesquisas, que não haja centros, associações que não estejam buscando isso; quero dizer que, quando se viaja pela América Latina hoje, percebe-se que "globalização" é um conceito muito reduzido, ou seja, para uns significa a dominação do capital (um puro avatar econômico) e para outros uma dinâmica tecnológica que por si mesma irá solucionar os grandes problemas políticos e culturais, quando esse conceito significa o entrelaçamento de processos muito complexos.

De alguma maneira, aquele momento tinha algo benéfico - que por sua vez também era traiçoeiro, enganoso - de que vivíamos uma visão unitária da luta, na qual deveríamos saber claramente quem era o inimigo. Lembro-me 
que, nesse texto, escrevi uma frase pela qual muitos me condenaram. Dizia que, naquele momento, estávamos começando a "não saber mais para quem trabalhávamos", para quem seria útil o que estávamos pesquisando. Ainda havia, portanto, uma convergência mas havia também uma espécie de força de tensão, ou seja, movimentos, dinâmicas que nos faziam compartilhar uma concepção de América Latina que precisava ser repensada à luz dos novos movimentos sociais que então surgiam, e fazer teoria começava a significar algo realmente estratégico para transformar nossos próprios países.

Hoje - e não posso dizer que a pesquisa seja menos ou mais séria - o que vejo é que aquela convergência e tensões que entrelaçavam pesquisas muito diferentes, provenientes diretamente daquela "pesquisa-ação" - da qual um dos criadores, Fals Borda (colombiano), de quem acabei sendo muito amigo, morreu no último fim de semana -, em que se tratava de se deixar questionar pelo que socialmente se descobria para transferi-lo para o campo da teoria, encontra-se modificada. Diria que qualquer mapa que façamos hoje é - foi sempre - muito mais incerto, precário, inseguro. O texto foi muito lido, e tenho muitas cartas que o testemunham: cartas de pessoas que viviam isso em seu trabalho em emissoras comunitárias, de pessoas que começavam a perceber que a tecnologia não era um simples fato material, mas que também passava a ter dimensões simbólicas, que toda aquela concepção instrumental dos meios não era suficiente, que os meios não eram mero instrumento, que a tecnologia não era apenas uma máquina, e que os processos internacionais faziam pensar em dimensões que não cabiam nas dimensões locais. Por isso, diria que havia certo bom senso naquilo que nomeávamos como grandes tensões e conflitos, porque as novas tecnologias já começavam a suscitar uma série de interrogações aos meios comunitários. Eram questões cruzadas entre as novas tecnologias e os novos modos de internacionalização, formando um campo de forças, um campo estratégico que se potencializava.

O que percebo atualmente é um campo da comunicação muito despotencializado. Se antes havia uma potencialidade que nos fazia pensar a sociedade, como transformá-la, minha opinião é que hoje o campo da comunicação foi, em grande parte, tomado por pessoas que podem ter muito valor, mas que o tornam cada vez mais neutro, mais despotencializado, mais - e aqui uso uma palavra daqueles tempos - «funcionalizado» a outras coisas, inclusive a grandes pesquisas.

Uma outra questão que gostaria de propor - embora seja apenas para precisar melhor como formular hoje esse mapa - é a conjuntura da pesquisa na universidade nos dias de hoje. Naquele tempo, tínhamos menos meios e recursos do que atualmente, entretanto a universidade hoje está bastante 
deslocada na sociedade. No Rio de Janeiro, houve um debate muito interessante, onde muitos me perguntaram: "Onde estão as universidades hoje"? Elas realmente têm ideia do que está acontecendo na sociedade? Ou continuamos a reboque do mercado de trabalho e é ele quem nos diz por onde ir e o que fazer? Nesses últimos anos, aí está a disputa do que, para mim, é hoje uma das dimensões mais pessimistas: para onde vão as universidades públicas? E o que vejo é que elas que foram «despolitizadas». Estou me referindo àquela politização de antes que, às vezes, tinha muitos defeitos, era muito retórica, saudosista, gritona, tinha muito de denúncia e poucas possibilidades de propor iniciativas, alternativas. Porém, mesmo com sua maneira confusa, permitia que a sociedade, que o país, estivesse permanentemente sobre a mesa de discussão. Contei-lhes as últimas coisas que ouvi nos seminários em que estive na própria Universidade Nacional de Bogotá (Colômbia), e minha desilusão com os alunos: eles continuam sendo gritões, derrotistas... porém, quando realizam os trabalhos finais, a imensa maioria está buscando claramente uma vaga no mercado de trabalho. Não há nada de mal nisso, mas há muito de mal quando cortam totalmente o que poderiam investigar; e me dei conta de que isso era totalmente esquizóide. Como estavam na Universidade Nacional, tinham que usar uma certa linguagem crítica, mas quando tinham que dedicar seu tempo a fazer os trabalhos, aí apareciam procurando empregos, e da maneira mais descarada.

Sinto que esses problemas para os campos estratégicos na universidade estão sendo pensados numa relação muito geral e, como toda generalidade, tal relação resulta muito caricata. Porém, desde que voltei de Guadalajara a Bogotá, depois de três anos lá, tenho dedicado meu trabalho a fazer ver tudo aquilo que, do país, não cabe nas universidades. Isso pode ser um pouco escandaloso, porém sinto que não sei se o país cabe mais na universidade do que na televisão. E olhe que na televisão cabe pouco país. Mas vejo também muito pouco país na universidade. Repito constantemente que é preciso colocar o país na pesquisa em comunicação, é preciso colocá-lo na pesquisa em ciências sociais. As pessoas estão estudando sociologia e economia, mas não estão estudando o país. Isso também é problemático na hora de poder nomear campos estratégicos. De tal modo que, com esses apontamentos, diria que hoje eu não conseguiria formular algo como aquele texto. Eu teria, primeiro, que encontrar uma maneira de definir, como fizemos então, o que entendemos basicamente por comunicação - porque é isso que se transformou, aquela compreensão de comunicação a partir da relação fundante, aquela "mediação comunicação e sociedade".

Hoje em dia aparecem duas palavras potentes: tecnologia e globalização. O que significa «tecnologia»? Milhares de coisas. Quando dizíamos "novas 
tecnologias", estávamos falando de satélites, de parabólicas, do início da eletrônica, mas sabíamos do que estávamos falando. Hoje, dizer «tecnologia»é dizer demasiadas coisas, mas com uma concepção que continua sendo ainda mais radicalmente instrumental, pois que instrumento estratégico do mercado. Mas pode-se notar que as próprias palavras foram implodidas. Noto que se há uma palavra com um campo semântico muito impreciso, nebuloso, confuso, é «tecnologia». Já não significa mencionar os meios que usamos, pois quando alguém dizia "meios" sabia o que estava nomeando. Hoje, quando dizemos tecnologia, não sabemos muito bem o que estamos nomeando. Porque, para alguns, são as últimas tecnologias, isto é, inclusive os últimos avatares, que significam muito pouco do ponto de vista comunicativo, mas podem significar muito de outros pontos de vista. Ocorre que começamos a criticar a «brecha digital», e quando se dizia "avanço tecnológico" perguntava-se sempre: "Sim, mas para «quantas» pessoas?" - somente para uma minoria, não para os bilhões que há no mundo. Atualmente, com os aparelhos de telefonia móvel, a maior parte da população na Colômbia urbana - que é mais de $75 \%$ do país -, sejam "deslocados" das guerras ou migrantes, já têm telefones celulares. Os pais o usam apenas como telefone, mas os filhos, nos finais de semana, já o utilizam para armazenar música, para colocar o álbum de fotografias da família. A brecha começou a ser quebrada muito antes do que tínhamos calculado, e eles hoje começam a se conectar. Os milhões de imigrantes colombianos que estão nos Estados Unidos e na Espanha estão utilizando o chat e o blog, estão usando tudo. Então, do quê estamos falando? É daqueles que têm menos posses, que pensávamos que demorariam séculos para se conectar e já estão conectados, e com uma enorme criatividade, porque isso permite novas formas de comunicação familiar e cultural. Dessa forma, essas pessoas estão conseguindo, de certo modo, se refazer como comunidade cultural; as avós podem acompanhar o crescimento dos bebês, ou mesmo as mães que os deixaram com as avós na Colômbia. O potencial social disso é enorme. Havia, em Valência (Espanha), um lugar que tem de tudo (telefone, fax, internet), e os donos eram colombianos. Um dia fiz uma enquete: como as pessoas usam isso? E descobri as muitas formas, diversas e criativas, com as quais elas estão se apropriando das novas tecnologias. Quando dizemos «tecnologia», o que estamos nomeando não é somente uma coisa mas um «âmbito» extremamente potente, tanto de linguagens como de ações, tanto de dinâmicas sociais, políticas e culturais, quanto de interrogações sobre o que significa «o social» hoje. Assim, quando passamos ao campo das interrogações, é que realmente explode a epistemologia, porque ainda há muita concepção instrumental - à direita e à esquerda - para falar das novas tecnologias. 
A outra palavra potente é «globalização». Como em relação à tecnologia, do que estamos falando quando falamos globalização? Há coisas que todos nomeiam - algo que hoje assusta o mundo -, a quebra dos grandes bancos financiadores, esses que não investiam na produção e só investiam na circulação. Assim, globalização é a dominação do novo capitalismo financeiro, ponto. Todo o resto é ideologia. Porém, a globalização está relacionada à mundialização, no sentido de que falam Milton Santos, Octavio Ianni, Renato Ortiz e Arjun Appadurai, e no qual está se construindo uma nova realidade histórico-social de interdependência, exigindo um novo pensamento radical para poder assumir a complexidade de uma cidadania mundial, de interações cada vez mais fortes entre culturas, de como ter políticas para defender a diversidade, e também de como guiar as trocas, as interações, para potencializá-las.

Vejo no momento uma impossibilidade para definir o «campo da comunicação» porque ele se espalhou para muitos lados, mas apontaria as tensões entre esses dois eixos, o das transformações tecnológicas e o das transformações globais que concernem «o mundo».

MATRIZES: Vocêfez uma afirmação bastante interessante: naquele tempo, sabíamos quem era o inimigo. Em termos do trabalho latino-americano como pesquisa nova (aquele que estávamos por refundar), de um pensamento crítico que não fosse também funcionalizado, você mostrava e mostra muito bem como os mais radicais e críticos podiam ser funcionalizados pelo sistema, ou seja, por uma paralisia pela qual acabava se aceitando o que já existia. Gostaria que aprofundasse a questão da «explosão» da comunicação, com que se rompe o rótulo da sua fragmentação e, principalmente, a questão da incerteza, e de como dar conta disso por meio da pesquisa.

Gostaria também de inserir uma visão simplificadora do funcionalismo contra a qual queríamos reagir, colocando outra coisa no lugar, tanto no sentido do pensamento complexo de Edgar Morin, como do sistema-mundo de Octávio Ianni e Immanuel Wallerstein. Queria que falasse daquilo que aparece hoje não tão bem situado como era antes, na nossa percepção de pesquisadores. Saindo de 1982, vamos para 1987, quando é publicada a primeira edição de seu livro De los medios a las mediaciones que, com a grande repercussão que alcançou e pelas questões epistemológicas que passa a levantar, tornou mais clara - pelo menos para o pensamento latino-americano - a questão de como lidar com essa complexidade.

Talvez agora, mais claramente do que antes - porque as questões epistemológicas do campo da comunicação passaram a ganhar legitimidade na América Latina -, continua na pauta de debates a questão do objeto da 


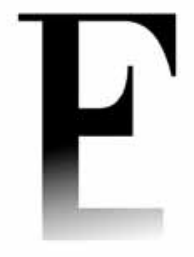

3. O prefácio aparece em português apenas a partir da segunda edição do livro. Ver Dos meios às mediações (2001).

comunicação: meios ou mediações? Mediatização ou mediação? Ou seja, a questão da comunicação é uma questão de meios ou de mediações? Faço essa pergunta para que responda precisamente este ponto: será preciso fazer um outro livro agora, intitulado Das mediações aos meios? Dentro desse quadro, gostaria de tratar sobre a questão das mediações e sobre as leituras que resultaram da repercussão do livro.

Martín-Barbero: Eu tracei um novo mapa, que incorporei no prefácio à quinta edição de De los medios a las mediaciones ${ }^{3}$. Trata-se de um mapa mais complexo, que foi emergindo das leituras que se faziam sobre o livro, e que eu nomeei como mediações sócio-culturais, mediações político-culturais da comunicação, para diferenciar esse mapa do primeiro, que se referia às "mediações culturais da comunicação". A partir daí, o que aparecia claramente eram dois eixos: um, as lógicas de produção e as competências de recepção; e outro, as matrizes culturais e os formatos industriais. Esse era o mapa das mediações culturais e sócio-culturais da comunicação. Foi uma primeira aproximação em uma conferência que fiz na Universidade Iberoamericana, em meados de 1990, em um seminário realizado por Guillermo Orozco - aos usos dos meios e às práticas comunicativas, e pela primeira vez comecei a pensar as mediações comunicativas da cultura. Ou seja, começo, então, a dar mais densidade epistemológica ao momento de conhecer o que vem da comunicação.

Parti da perspectiva de que estudar a comunicação era estudar os meios, que era o que nos chegava do norte, e eu dizia “não!". Quando saio às ruas na Colômbia, vejo que as pessoas se comunicam e investem muito mais tempo na comunicação familiar, na comunicação no trabalho, na comunicação no bairro, na comunicação religiosa, na comunicação festiva, na comunicação lúdica. Foi isso que tentei colocar como objeto de estudo naquela pesquisa inicial, que foi minha primeira no campo da comunicação: comparar como as pessoas se comunicam em um supermercado e numa praça de mercado popular. Enquanto no supermercado não havia comunicação, ninguém falava com ninguém, havia somente informação, informação publicitária, nada mais, na praça do mercado popular, todas as pessoas falavam, gritavam, trocavam, aproveitavam o encontro para falar sobre a vida; ali estava cheio de comunicação. E era isso que queria colocar como primeiro elemento naquela pesquisa.

A pira comunicativa da nossa sociedade é muito mais rica e muito mais ampla do que permitem os meios. Os meios podem ser influentes, e são importantes. Porém, além de toda a mediatização das campanhas políticas, na Colômbia os presidentes eram eleitos com 30\% dos votos da população; $70 \%$ não votavam. Falava-se da importância política dos meios por si. Mas em que país? Se nos Estados Unidos, metade da população já não votava, agora vota 
menos. E na Colômbia, votavam apenas 30\%,35\%. E eu dizia: onde está o poder dos meios? Eu via que as pessoas votavam em alguém porque elas nasciam conservadoras ou liberais, ou seja, ser conservador ou liberal era uma questão familiar, de parentesco. Por exemplo, se a família era conservadora e uma filha era comunista, o que tinham os meios a ver com isso? Os liberais continuavam votando em liberais, não importando se o candidato fosse bom ou ruim. $\mathrm{O}$ que eu queria pensar era a força social, cultural e política da vida cotidiana, da comunicação entre vizinhos, entre amigos do mesmo time de futebol, e também entre os governantes e os governados.

Entretanto, em meados de 1990, as coisas começaram a mudar e fiz uma descoberta sobre a qual não cheguei a escrever, mas da qual falo muito agora: dei-me conta que havíamos passado anos criticando como meramente alienante a presença dos programas de ficção norte-americanos na televisão latinoamericana, todos aqueles programas de tribunais, de advogados, de policiais, o seriado Columbo... Comecei a me dar conta que a televisão norte-americana foi o ator que mostrou o divórcio como direito sócio-cultural, mostrou que as mulheres tinham outro estatuto social. E isso jamais havia sido apreendido pela esquerda como uma contribuição para tornar mais livres e laicas nossas sociedades. Assim, quando a constituição colombiana declarou que o país tinha uma sociedade não confessional, que é uma forma indireta de dizer que a sociedade é realmente laica, de separação entre Igreja e Estado, havia muito que agradecer à televisão norte-americana, porque ela, com suas séries, mundializou as pessoas, com os divorciados, os homossexuais, pois criou um ambiente que fez parecer possível e desejável aquilo que a religião havia proibido como antinatural.

Portanto, começo, por um lado, a olhar isso de outra maneira; e, por outro, noto que a telenovela colombiana havia se adiantado à Constituição de 1991, com a primeira representação não-negativa das culturas nacionais, porque era irônica. Havia ironia, mas as pessoas do centro já sentiam que os caribenhos não eram somente dança e sexo, que ali havia outra cultura, rica, sensual, alegre, informal, contra a tristeza dos andinos. Recoloco assim uma questão decisiva: a presença dos meios na vida social, não em termos puramente ideológicos mas como uma capacidade de ver além dos costumes, ajudando o país a se movimentar. Isso me leva a dar mais um passo, junto com a aparição massiva, em meados de 1990, do computador e do que veio rapidamente com ele. Inverto meu primeiro mapa e proponho as "mediações comunicativas da cultura", que são: a "tecnicidade"; a "institucionalidade" crescente dos meios como instituições sociais e não apenas aparatos, instituições de peso econômico, político, cultural; a "socialidade" - como o laço social está se transformando para os jovens, como as relações entre pais e filhos, e entre casais, estão mudando. Isso vem 
dos costumes dos avós, das matrizes que não se pode negar, pois estão aí. Nós, pais, estamos sofrendo a contradição: o que não pudemos fazer, nossos filhos poderão - a famosa reflexão de Margaret Mead sobre a geração intermediária. E, finalmente, as novas "ritualidades" que acontecem em relação aos novos formatos industriais possibilitados pela tecnicidade. De alguma maneira, nesse momento aceito que muda o lugar a partir do qual estava olhando. Olhava a partir da nossa cotidianidade comunicativa latino-americana, rica, festiva, e a contrapunha à solidão dos norte-americanos, pois nós, latinos, desfrutamos mais estando juntos do que sozinhos, e os anglo-saxões desfrutam mais estando sozinhos diante de um copo de cerveja, ou de um brandy, do que juntos; quando estão juntos, enlouquecem, como demonstram os hooligans ingleses ou holandeses! Era preciso assumir não a prioridade dos meios, mas sim que "o comunicativo está se transformando em protagonista de uma maneira muito mais forte".

Outra coisa que teve muito peso para esta mudança foi o artigo de Giuseppe Richeri sobre como a política estava cada vez mais vazia, mais incapaz de se comunicar com a nação, de convocar as pessoas. Assim, o que coloca em comunicação as pessoas que estão perdidas nas grandes cidades é o rádio e a televisão. E as comunidades de telespectadores de vídeos e de telenovelas, que a distância compartilham uma intriga, um suspense, mas também compartilham certa intensidade de vida, porque a vida é sempre mais intensa na ficção do que na cotidianidade.

As pessoas estão cada vez mais isoladas, mais sozinhas, também nos países latinos, e os meios começam a ter uma importância enorme em termos do que chamamos de "cultura a domicílio". As pessoas já não tinham dinheiro para sair, mas a televisão lhes provê de tudo; depois veio o vídeo e muitas pessoas com baixo poder aquisitivo compraram um aparelho. Lembro-me o escândalo quando comecei a ver na Colômbia - depois da nova Constituição - que todos os feriados, salvo dois nacionais, haviam passado para as segundas-feiras, ou seja, caísse quando caísse o feriado, ele seria celebrado na segunda-feira seguinte. E agora temos esses finais de semana longos, sábado, domingo e segunda. Quando comecei a ver em Cali (morava em um bairro de classe média) que as pessoas alugavam, nas sextas-feiras, quinze, vinte filmes - num lugar em que faz muito calor, onde há o rio para se refrescar, onde há piscinas -, eu não entendia por que elas alugavam tantos e levavam para casa para ficar todo o tempo fechadas, vendo filmes. Depois, fiz uma pequena pesquisa que me mostrou por que as pessoas se fechavam em casa e o que significava ter cinema em casa - cinema que «elas» escolhiam, cinema mexicano, quase todo em castelhano, pois não podiam ver com legendas senão não seguiam o filme. Eu já estava repensando 
essas questões, tinha que fazer uma mudança que não era ir das mediações aos meios, mas perceber que a comunicação se adensava diante da nova tecnicidade, era a "institucionalidade" da tecnicidade. Pode-se continuar falando «das mediações dos meios», mas «mediação" para mim sempre foi outra coisa que tem muito mais relação com as dimensões simbólicas da construção do coletivo. Preferi falar então de "mediações comunicativas da cultura", e quando digo da cultura não falo somente de seus produtos, mas digo da sociedade, da política.

Esta foi a mudança. E esta mudança, para mim, foi muito importante porque me permitiu colher o melhor Jürgen Habermas, aquele capaz de pensar as "transformações dos laços sociais", pensadas em termos de identidade sóciocultural, ou seja de identidade do afro-colombiano, da mulher, do indígena, de um novo modo de relação, de reconhecimento pela sua sociedade jurídica e política. Isto é, o estudo da "socialidade" que está ligada ao livro de Habermas sobre a crise da modernidade, o que recolhe a comunicação na crise da modernidade. Quando ele diz: "Já estamos diante de uma sociedade que não tem centro...", pois o centro era a política, a religião, e nem a religião ou a política dão coerência à sociedade. Quando a sociedade não tem centro, as identidades que eram o centro do sujeito também deixam de sê-lo. Até Habermas admite que já não é possível falar de apenas uma identidade do indivíduo porque seus referentes das identidades também explodem. Era preciso acompanhar como estavam se transformando as maneiras de sentir, o laço social que religa uns a outros, porque esta é a dimensão que fala na identidade. A identidade é o que há em comum, ou seja, eu tenho uma identidade jovem, eu tenho uma identidade brasileira, eu tenho uma identidade paulista, eu tenho uma identidade feminina, é o conjunto das religações sociais.

A mudança foi esta: reconhecer que a comunicação estava mediando todos os lados e as formas da vida cultural e social dos povos. Portanto, o olhar não se invertia no sentido de ir das mediações aos meios, senão da cultura à comunicação. Foi aí que comecei a repensar a noção de comunicação. Então, a noção de comunicação sai do paradigma da engenharia e se liga com as «interfaces», com os «nós» das interações, com a comunicação-interação, com a comunicação intermediada. A linguagem é cada vez mais intermedial e, por isso, o estudo tem que ser claramente interdisciplinar. Ou seja, estamos diante de uma epistemologia que coloca em crise o próprio objeto de estudo. Porque acreditávamos que existia uma identidade da comunicação, que se dava nos meios e, hoje, não se dá nos meios. Então, onde ocorre? Na interação que possibilita a interface de todos os sentidos, portanto, é uma "intermedialidade", um conceito para pensar a hibridação das linguagens e dos meios. É dizer que, cada vez mais, o rádio é cada vez menos somente rádio; o rádio hoje oferece 
programas que são blogs, no qual alguém fala, outras pessoas falam, e volta a falar o senhor ou a senhora; os gêneros estão sendo reinventados à luz da interface da televisão com a internet. Porque intermedialidade não é a transposição do conceito literário de intertextualidade, não é a mera relação entre textos que já existem, mas como diz um autor canadense, é a ideia de "vírus": alguns gêneros geram vírus que penetram e contaminam outros meios. Achei isso valiosíssimo. Ou seja, estamos ante uma interação que desestabiliza os discursos próprios de cada meio. Então estamos ante formas mestiças que começam a ser produzidas, formas incoerentes porque rompem a norma atuando transversalmente em todos os meios. Não é uma coisa racional como a intertextualidade que está sob o que foi escrito, que é tudo o que foi lido. É a contaminação entre sonoridades, textualidades, visualidades, as matérias-primas dos gêneros.

MATRIZes: Como você vê a transdisciplinaridade nos estudos de comunicação? Ela está sendo praticada? Com base no que afirmou agora, de que o estudo da comunicação só pode ser transdisciplinar, como ela pode ser efetivamente praticada? E como deve ser formado esse pesquisador?

Martín-Barbero: Primeiro, interdisciplinaridade não é negação das disciplinas, não é antidisciplina, embora em certos países, como na Colômbia, fosse preciso iniciar indisciplinando os saberes sociais porque são extremamente disciplinados. Diria que há dois horizontes para se entender a fundo a questão. Eu estava apresentando seminários sobre isso em vários países a partir de uma conferência na Universidade Nacional, uma conferência inaugural na Faculdade de Ciências Humanas e Sociais, intitulada Transdisciplinaridad: notas para un mapa de sus encrucijadas cognitivas y sus conflictos culturales. Ao mesmo tempo, vinculei-me de novo à Universidade del Valle (Cali) para montar o doutorado em Ciências Humanas. Elaborei então um documento para defender, até no Ministério da Educação, a transdisciplinaridade entre filosofia, história, estudos da linguagem e literatura. E nessa ocasião, descobri o primeiro encontro da Unesco, criando, com Basarab Nicolescu, um físico romeno, e com Edgar Morin, o Núcleo de Transdisciplinaridade da Unesco; seu manifesto é de novembro de 1994. Mas as origens da transdisciplinaridade remetem ao ano de 1944, um pouco antes de terminar a guerra mundial, no MIT, quando se reúnem, com Norbert Wiener, um neuropsicólogo, Arthur Rosenfeld; um psicólogo, Kurt Lewin; e um jovem antropólogo, Gregory Bateson. Eles propõem que o futuro da pesquisa científica já não está no centro de cada disciplina, mas nas zonas de fronteira, o que eles chamam de "as regiões fronteiriças", entre biologia, psicologia e física, ou seja, é preciso então passar dos objetos que nuclearam as disciplinas 
para os das zonas de fronteira, entre sociologia, biologia e psicologia, por exemplo. Isso me pareceu o verdadeiro manifesto da transdisciplinaridade, e com uma perspectiva ainda mais abrangente. O que eles justificam é que os núcleos das disciplinas se tornaram duros, se tornaram obstáculos, não permitindo o avanço "nos lugares onde uma disciplina toca e cruza a outra", que é justamente onde florescem os temas a serem desenvolvidos. Ou seja, é necessário "desencapsular" a pesquisa científica, que é a mesma proposta de Wallerstein em Abrir as Ciências Sociais. Entre a proposta dos cientistas de MIT e o Manifesto da Unesco, há um texto de Jean Piaget, de 1972, em que encontramos a seguinte frase: "Podemos esperar uma etapa nova da ciência que seria transdisciplinar, pois não se contentaria em compensar as interações, reciprocidades entre conhecimentos especializados, mas situaria essas relações no interior de um sistema sem fronteiras entre as disciplinas".

As três «introduções» à transdisplinaridade têm basicamente dois argumentos em comum. O primeiro é que a especialização, a hiperespecialização da pesquisa, está impedindo a compreensão do social, do humano, do real. Em outras palavras, a hiperespecialização é o que impede pensar em conjunto os problemas da sociedade, os problemas da humanidade, porque cada vez o conhecimento é mais fragmentário. Pode ser muito avançado, mas é um fragmento. Desse modo, é impossível pensar a sociedade, pensar o mundo, pensar a humanidade. O segundo argumento é que não se trata de somar resultados. É feita uma clara diferenciação entre multidisciplinaridade, na qual há uma reunião de resultados de diferentes disciplinas, e interdisciplinaridade, em que já há algum tipo de transferência de métodos; e mais ainda com a transdisciplinaridade, quando as disciplinas entram em crise na própria identidade: o que é propriamente cognoscível, pesquisável, a partir de cada uma delas? Pois uma coisa é a capacidade que tem uma disciplina de «construir» um objeto de conhecimento, e outra coisa é que esse objeto seja tomado como «propriedade exclusiva» dessa disciplina.

MATRIZes: Esta seria a crise da visão do sujeito?

Martín-Barbero: A crise do sujeito que acredita ver tudo olhando apenas de um ponto. Em minha opinião, o mais importante em tudo isso é que muitos pensam que a interdisciplinaridade e a transdisciplinaridade sejam contos das ciências sociais que, como estão cada vez mais perdidas, agora inventaram essa «moda», quando na verdade foi nas "ciências duras» que a questão teve início. Dá para acreditar que, no núcleo transdisciplinar da Unesco, somente Morin seja das humanidades e que todos os demais sejam físicos, biólogos, matemáticos? Os exemplos que se propõem no Manifesto Unesco são todos 
referidos à relação da matemática com a neurologia, ou de como foi criada a física-matemática. Ou seja, como se transportou isso até criar no interior novas ciências que são híbridas, que já são formadas por várias disciplinas e que já têm uma entidade com aplicabilidade manifesta muito mais avançada do que se poderia imaginar nas ciências sociais.

Eu diria que, no caso da Comunicação, do ponto de vista epistemológico acredita-se ser impossível atribuir a uma disciplina o conjunto de saberes que o estudo dos processos de comunicação mobiliza; não é possível dizer que a psicologia é a mãe da comunicação, nem a psicologia behaviorista norteamericana, nem sequer outras teorias cibernéticas. Depois disso, passamos para a semiótica, porque é mais rica em conteúdo, vínculos. Mudamos para uma maior complexidade para colocar o qualitativo onde não havia mais que o quantitativo. Nada disso tem a mínima capacidade para abarcar sequer dez das dez mil variáveis que existem hoje na comunicação. Reafirmo que a comunicação é um campo de conhecimento e que jamais foi uma disciplina. Houve um tempo em que me pediram para traduzir livros norte-americanos porque eles diziam que já haviam pesquisado tudo em termos epistemológicos, que já estavam estudando tudo a partir de psicologia, cibernética, análise de sistemas. Por favor, sejamos sérios. Comunicação «nunca» foi pensada como tal dentro do paradigma da engenharia proposto por Shannon para estudar a economia de circulação da informação. O que foi pensado por essa teoria chamada de Teoria Geral da Comunicação era a transmissão de sinais em termos econômicos, de como gastar menos energia na engenharia telefônica! E sua hegemonia decorreu do fato de que foi escrito em inglês e nos Estados Unidos, onde o behaviorismo reduzia a ação a seus efeitos imediatamente constatáveis e medíveis, pois sem isso jamais teria desempenhado o papel que teve na confusão da comunicação com a transmissão a distância. Mas o que potencializou essa teoria foi o fato de que alguns autores, como Lazarsfeld e Lasswell, transformaram-na em paradigma de análise dos efeitos do discurso publicitário e do discurso político sobre a população massiva. De fato, foi assim que se passou a acreditar na existência de "uma disciplina da comunicação". Para mostrar a pobreza conceitual dessa teoria, eu pedia a meus alunos para "analisar» comunicativamente um baile, com os corpos dançando, onde estava o canal, onde estava o emissor, onde estava o receptor! $\mathrm{Ou}$, em uma cerimônia religiosa, a missa, para quem acredita, um rito que durante séculos foi realizado em latim e de costas, ninguém entendia nada, e, no entanto, havia uma comunhão, havia uma experiência de comunidade. E claro que não estamos diante de um objeto definido por uma disciplina, estamos diante de um campo de conhecimentos antropológicos, sociológicos, semióticos, políticos etc. 
Sobre a outra pergunta: sim, seria necessário incluir a transdisciplinaridade no ensino médio, porque nesse período os estudos acontecem em compartimentos estanques, e o dualismo que vem do religioso, essa incapacidade de diferenciar sem opor, é aprendido, porque os que nasceram no catolicismo não sabem diferenciar sem opor. $\mathrm{O}$ que sempre pergunto a meus alunos como prova disso é: “Quando as crianças começam a entender/desfrutar o filme?”. Quando se identifica o bem e o mal. Se não os identificam facilmente, se aborrecem, não entendem o filme. Aqui há um problema muito sério, porque para pensar transdisciplinarmente é necessário superar o dualismo, pois o dualismo é, em termos epistemológicos, a simplificação máxima do complexo e, portanto, a impossibilidade de pensar a ambiguidade e as contradições. Em minha luta contra o dualismo, aplicava as provas aos alunos e depois anotava nelas a quantidade de dualismos que havia, e contra os quais havia explicado na aula. Eu lecionava dois semestres de Estética. Primeiro, explicava as grandes correntes de estudo de arte, filosofia, sociologia, porém mostrava como a filosofia tendia a pensar a arte além das épocas históricas, era algo à margem do capital, apenas arte, pois a sociedade, a economia, a política mudavam e, no entanto, aquela arte continuava emocionando. Depois, explicava como a sociologia e, sobretudo, uma sociologia crítica, que se aproximava do marxismo, mostrava por que a arte tinha relação com sua sociedade. Essas duas explicações são modos conplementares de ver, e não oposições. É preciso saber filosofia, olhar a estética do ponto de vista do que se constrói como dimensão do humano, e também é necessário ver que isso também tem uma história social. Entretanto, os alunos não conseguem entender isso. Não podiam aceitar o sentido da «diferença», e reiteravam o que pensavam antes: ou a arte era algo com especificidade, ou a arte era reduzida ao que eram «suas» condições históricas.

Há mudanças que vão além disso. Hoje as crianças misturam tudo, porque não têm apenas a escola como âmbito de conhecimento, de informação. Porém, a escola forma-os como dualistas, forma-os separando tudo: o campo social por aqui, o campo das ciências naturais por ali, e a literatura acolá. A proposta que faço para a reforma da universidade é que há três saberes indispensáveis: saberes históricos, saberes lógico-matemáticos e saberes estéticos. Vejo que, por aí, começaremos a ruptura dos saberes disciplinares. De quem pensa que para formar um cidadão, para fazê-lo entender o mundo, para localizá-lo neste planeta, é necessário um mínimo de saber histórico, de saber colocar em perspectiva o que se sente; não me atrai o palavreado, pois, para mim, os saberes históricos são o oposto, é escolher o hoje. Um problema deste país é dizer: como colocamos isso em história? Com o que está relacionado? Está relacionado com a economia, a política, a cultura? Não há nenhuma causa única do que somos. 
A economia teve seu papel, a política ainda mais. Mas o que é este país? Então, devemos incluí-lo «em» história, educar as pessoas para que façam esse exercício de colocar em perspectiva histórica o que se vive hoje. Depois, colocá-lo em perspectiva lógico-matemática, lógico-simbólica, porque é a linguagem das novas destrezas cognitivas e criativas. E saberes estéticos, que são os «saberes da sensibilidade», todo o saber que passa pela expressividade em todas as suas modalidades, tanto artísticas como a criatividade que existe no «saber-sentir».

$\mathrm{E}$, se começarmos a reformar a universidade, teremos que nos esforçar para sair dos preconceitos que temos em relação aos jovens e fazer junto com eles um caminho investigativo e de acompanhamento para saber com que bagagem chegam realmente, não aplicando um exame e sim em termos do que significa para eles o conhecimento, o que significa aprender, quais são seus problemas para ler, para escrever, para desenhar, para usar uma câmera etc.; poder ver, por exemplo, que há aqueles que não escrevem e que possuem outras capacidades de se expressar. Ou seja, o que devemos fazer para que estes saberes - histórico, lógico-matemático e estético - se relacionem com sua própria capacidade de contar histórias. Assim, pode ser que consigamos quebrar os compartimentos que trazem. Atualmente trabalho em uma proposta de um novo tipo de currículo. A ideia é que, durante um ano, todos os alunos dos diferentes cursos fiquem juntos; depois, terão dois anos nos quais serão ministradas as disciplinas de suas «especialidades», mas vão estudar durante esses dois anos (por quatro semestres) uma disciplina - que pode ser matemática, história, filosofia, ou seja, que escolherão - para a qual terão um tutor para quando necessitarem. Se estudarem filosofia, serão quatro semestres de filosofia dentro de um programa de estudos para este aluno ou aluna, porque é muito importante que tenham um outro saber distinto de seu saber específico e, quanto mais tiverem isso (matemática, filosofia, antropologia, história), mais estarão compensando a compartimentalização. O último ano será de prática social, voltarão a se reunir em equipes para fazer o trabalho final de graduação, que deve ser uma pesquisa e práticas sociais.

MATRIZes: Apesar de seu pessimismo em relação à fragmentação do campo, quais seriam as principais contribuições que os estudos ou o pensamento latino-americano podem trazer hoje para o campo geral da comunicação?

Martín-Barbero: Acredito que possam ser três. Uma, que já iniciamos seriamente, é a superação da visão instrumental. Em outras palavras, estamos passando gradativamente de uma visão predominantemente instrumental, ainda que adornada de aspectos sociais ou culturais, para uma visão mais densa de comunicação, densa culturalmente, densa socialmente. Já não é tão 
fácil confundir a comunicação com os meios. Ainda há muito disso, porém há também fortes núcleos que realmente incorporaram a dimensão cultural como dimensão profunda, heterogênea, que já não está simplesmente relacionada com a cultura, mas com a diversidade, com a heterogeneidade, em todos os sentidos. Significa, a meu ver, que o primeiro avanço que existe é que a visão instrumental tem que, de alguma maneira, ser cotejada com esta outra visão, todavia ainda minoritária, que insere a comunicação nas práticas, nas transformações que afetam todas as dimensões da vida. Isto é, a comunicação é a grande metáfora desta categoria que foi tão importante dentro do marxismo, a categoria da "troca". E eu quero recuperar essa categoria de troca, sobretudo à qual nos levou Baudrillard com A troca simbólica e a morte, que é uma reflexão preciosa. A sociedade é feita de trocas. As categorias que hoje deveriam ser retomadas para se pensar a comunicação são "troca" e "interação".

Hoje mesmo, quando falamos de tecnologia estamos nomeando uma mediação simbólica, cada vez mais estamos falando de um "ecossistema" comunicativo, falamos do conceito de "entorno". O primeiro, o entorno ecológico, é o mundo vegetal e animal; o segundo, o institucional, onde se situam as cidades, as instituições políticas, os impérios, os estados, juntamente com sociedade. Agora vivemos também em um entorno "comunicativo", esse entorno técnicocomunicativo com suas linguagens, escrituras e gramáticas novas. E assim a concepção de comunicação vai se tornando muito mais capaz, «epistemologicamente», de dar conta do que ocorre na vida social, com as tecnologias de comunicação transformando-se de instrumento pontual em ecossistema cultural.

O segundo avanço, para mim, tem relação com essa nova bagagem epistemológica e operacionalidade metodológica. Pode parecer estranho que o coloque desse modo, mas quero dizer que seu livro Vivendo com a telenovela, para mim, marcou um ponto de inflexão: vocês conseguiram compor uma proposta de pesquisa que articula saberes diversos, ou seja, articula-os e fortalece-os ao reuni-los, e também é uma proposta operacional que chega até o uso de um programa de computador, uma proposta digital para poder lidar com a quantidade de informações, resgatá-las em seu valor qualitativo, já que não oferece apenas estatísticas, mas dimensões que não seriam visíveis se não mediante esse tipo de tratamento numérico. Diria que agora isso está acontecendo cada vez mais, propondo formas de investigação que priorizam estas questões. Por exemplo, acabo de ler um livro de pesquisa sobre jovens que traz uma leitura dos modelos sobre as grandes imagens que os jovens constroem a partir dos meios. Nada de "vamos ver que ideologia eles têm", ou "como se reproduz a ideologia dominante". Vamos ver quais são os fundamentos com os quais os meios impressos compõem uma imagem que, por um 
lado, é rentável para o mercado e, por outro, é tranquilizante para os pais de família. Isso é diferente. Aqui há uma mistura de métodos para poder fazer esse tipo de análise de quais são os núcleos de imagem sobre contos heroicos que os meios impressos transmitem. O que é novo é a densidade da análise, em que são diferenciados aspectos que pareceriam muito positivos de outros aspectos fortemente manipulados.

E o terceiro avanço: penso que a maneira como as coisas estão sendo realizadas contrapõem meu pessimismo, pois ultimamente estou além do otimismo e do pessimismo, pois agora, na velhice, tenho esperança, mas no sentido que dizia Walter Benjamin, que a esperança apenas nos é dada por meio dos desesperados. Nunca, na América Latina, houve tanta gente desesperada como hoje. O desespero é rebeldia, desperta muito mais capacidade para imaginar saídas, para imaginar formas de união, formas de luta, não para dizer ao mundo que não é o mesmo, mas sim para mudar coisas na vida, no campo, na cidade. Em Bogotá, vemos claramente como o prefeito, um pedagogo, um grande comunicador, valorizou milhões de cidadãos, porque o único modo de transformar Bogotá era que cada um sentisse que Bogotá era sua; porque falar sobre os maus serviços de tráfego, de água, de energia, de saúde, e não haver ninguém a quem responsabilizar, não adianta, pois a cidade é o que fazemos dela.

A relação comunicação-sociedade - esta que eu dizia ser a comunicação fundadora da crítica, do pensamento crítico - é hoje muito menos ideologizada, muito menos aparentemente presente, porém, para mim, está relacionada com a maneira como vão sendo construídas as mediações de comunicação e país, de comunicação e América Latina, de comunicação e mundo-local, de comunicação e cidade-município, ou seja, já não é a sociedade, é o município.

MATRIZes: Seria outra maneira de colocar as intervenções nas brechas?

Martín-Barbero: Sim, é isso. As «brechas», ou seja, tanto as grandes contradições do capitalismo como as pequenas contradições cotidianas, a partir das quais eu posso dinamizar um grupo social. Há uma imagem disto, que para mim é muito preciosa, com a qual podemos ver como passamos de meios de comunicação popular, de comunicação alternativa, a essa ideia de "meios cidadãos". Quando falávamos de "alternativos" significava que "ser pequeno é ser lindo", pois quanto menor a experiência, mais bela ela seria. Mas também significava ser a alternativa aos meios grandes, mentirosos, completamente entregues ao imperialismo. Comunitário significou algo diferente do alternativo, significou uma democratização porque, no fundo, os alternativos sempre se guiaram pela vanguarda política e sempre foram muito pouco democráticos. Lembro-me de quantas vezes me convidavam para ir a seminários de meios populares e as 
pessoas, quando eu perguntava como aquilo funcionava, começavam a contar a verdade, que era uma negação do que pregavam; queriam sempre democratizar a sociedade, porém no grupo sempre havia um ou dois que detinham o poder e os outros eram «burros de carga», «carregadores de pedras», como dizemos na Colômbia. Comunitário passou então a significar uma democratização interna dos meios, participação de mulheres, crianças, jovens. Entretanto, agora, na Colômbia, vamos dar um passo à frente. Uma das áreas da Comissão Nacional de Cultura é a de "meios cidadãos", ou seja, meios que falando da vida no bairro, do município, olham para o país, têm coisas a dizer ao país. Trata-se de ser a expressão da vida cotidiana das pessoas, de um bairro, de um município, da zona mais dura da guerra, mas interpelando o país. Minha luta agora é brigar com a ministra da comunicação, porque ela não permite que os meios cidadãos entrem em rede. Ou seja, qualquer emissora privada pode entrar em cadeia com qualquer outra do mundo, isso não é problema. No entanto, não deixam que os meios cidadãos possam entrar em rede e transmitir um programa inteiro de alguém que fale ao país. Por isso, propus que, na Rádio Nacional da Colômbia, haja pelo menos uma hora semanal que seja deles.

O que quero dizer é que estamos falando do que acontece em nossos bairros, em nossos povoados, mas também temos coisas para dizer ao país, não apenas para pedir, mas iniciativas para propor, ideias para colocar em debate. $\mathrm{O}$ governo não deixa que entrem em cadeia, porque já há toda uma infraestrutura tecnológica e todos poderiam se conectar. Então, um dia, eu transmitiria o programa de alguém de um pequeno povoado na serra, outro dia transmitiria um projeto precioso que tenha sido realizado em um bairro no centro de Bogotá, porque as comunidades são uma organização, não estão isoladas, e cada vez têm acesso a mais programas de outros países, estão cada vez mais mundializadas, mais latino-americanizadas. Esta, para mim, é a nova face da relação comunicação-sociedade. O fato mais importante que está ocorrendo na comunicação não é o que está acontecendo na tecnologia, mas na comunicação como uma chave de transformação política, como esboço de uma nova democracia. Isto é, as pessoas sabem que, na comunicação, começam a ter um poder que nunca tiveram, que não é só a palavra, são os contos, músicas, narrativas, não apenas a transmissão da palavra mas a visibilidade política para se fazerem presentes com novas formas de cidadania. Acredito que isso é fundamental. Está ocorrendo agora, e é o que me dá esperança. M

Como última parte da entrevista, Jesús Martín-Barbero indicou uma bibliografia básica composta por uma dúzia de obras que mais influenciaram seu pensamento. Ela está relacionada a seguir: 
ADORnO, Theodor y HORKHeIMER, Max (1971). Dialéctica del iluminismo, Sur, Buenos Aires.

BENJAMIN, Walter (1982). Discursos interrumpidos, Taurus, Madrid.

DE CERTEAU, Michel (1980). L'invention du quotidien 2: arts de vivre, U.G.E-10/18, Paris.

GARCÍA CANCLINI, Néstor (1990). Culturas híbridas, Grijalbo, México.

GRAMSCI, Antonio (1977). Cultura y Literatura, Península, Barcelona.

HOGGART, Richard (1972). The Uses of Literacy. Penguin, Londres.

LECHNER, Norbert (1990). Los patios interiores de la democracia, Flacso, Santiago de Chile.

MORIN, Edgar (1962). L'esprit du temps, Grasset, Paris.

RICOEUR, Paul (1969). Le conflit des interpretations, Du Seuil, París.

ROMERO, J. L. (1976). Latinoamérica: las ciudades y las ideas, Siglo XXI, México.

SANTOS, Milton (1996). A natureza do espaço, Hucitec, São Paulo.

WILliams, Raymond (1980). Marxismo y literatura, Península, Barcelona.

\section{Obras citadas pelo autor}

BAUDRILLARD, Jean (1996). A troca simbólica e a morte. São Paulo: Loyola.

HABERMAS, Jürgen (1975). Problemas de legitimación en el capitalismo tardio. Buenos Aires: Amorrortu.

(1989). El discurso filosófico de la modernidad. Madrid: Taurus.

LOPES, Maria Immacolata Vassallo; BORELLI, Silvia Helena Simões; RESENDE, Vera da Rocha (2002). Vivendo com a telenovela. Mediações, recepção, teleficcionalidades. São Paulo: Summus.

MARTÍN-BARBERO, Jesús (1982). Retos a la investigación de comunicación en América Latina. Comunicación y Cultura, 9. (1987). De los medios a las mediaciones. Barcelona: Gustavo Gili. (2001). Dos meios às mediações. Rio de Janeiro: Editora da UFRJ, 2001. (2005). Transdisciplinaridad: notas para un mapa de sus encrucijadas cognitivas y sus conflictos culturales. In: Jaramillo, J. Eduardo (comp.). Culturas, identidades y saberes fronterizos. Bogotá: CES/UN.

MEAD, Margaret (1977). Cultura y compromiso. Barcelona: Granica.

PIAGET, Jean (1972). L'interdisciplinarité. In: Apostel, Léo, Berger, Guy, Briggs Asa e Michaud, Guy (ed.). L'interdisciplinarité - Problèmes d'enseignement et de recherche. Paris: Centre pour la Recherche et l'Innovation dans l'Enseignement, Organisation de Coopération et de développement économique.

WALLERSTEIN, Immanuel et al (1996). Abrir as Ciências Sociais. Lisboa: Europa-América. 
